\title{
EXHIBITION
}

\section{Capturing colours of times past}

\section{Laura Spinney}

In these days of digital cameras and Photoshop, it is hard to imagine the wonder that instant photography and the first colour photographs inspired. It comes as a revelation to witness a landscape striped by lightning in daylight through the eyes of the photographer who first captured it; to stand beside him in a mocking crowd, as he points a camera at fireworks exploding in the night sky; or to feel his embarrassment as he asks the King and Queen of Denmark to hold their poses for a few seconds.

In all three cases, the photographer was the Frenchman Léon Gimpel. He took up photography just as it was moving away from science to become an art, but was still developing rapidly. His inventive use of the medium helped drive that development. Today Gimpel is barely known because the techniques he experimented with and improved upon were superseded and became obsolete. In his lifetime, his work was considered revolutionary.

Gimpel's images are the subject of a new exhibition at the Musée d'Orsay in Paris, organized in collaboration with the French Society of Photography. The pictures are accompanied by extracts from L'Illustration, the newspaper to which he contributed for 30 years.

Using autochrome, a predecessor of colour photography using starch on a glass plate patented by the Lumière brothers in 1907, Gimpel was one of the few to capture the colours of the Belle Epoque - the 'beautiful era' from the 1890s to the start of the First World War. With others he found a way of increasing the sensitivity of the autochrome plate, so that he no longer had to use a tripod or ask his subjects to sit patiently. Thus colour photography became instant. Gimpel exploited the innovation to chronicle the technological advances of the age, from the birth of aviation to the advent of neon light. He also captured human scenes - the nocturnal life of Paris; the poorly lit interiors of pre-war France.

Each image is also a tale of technical obstacles overcome, of curiosity, experimentation, perseverance and triumph. Many appeared first in the pages of L'Illustration, where their reproduction was itself a feat, and mounting the fragile glass autochromes has in turn tested the exhibition's curators. Backlit by a cold light, what is so striking about the colours is how pale and delicate, not to say washed out, they are to over-stimulated, modern eyes, and somehow, all the more moving for it.

Laura Spinney is a science writer based in London and Paris. Her latest novel, The Quick, is out in March. the Musée d'Orsay, Paris (www.musee-orsay.fr).

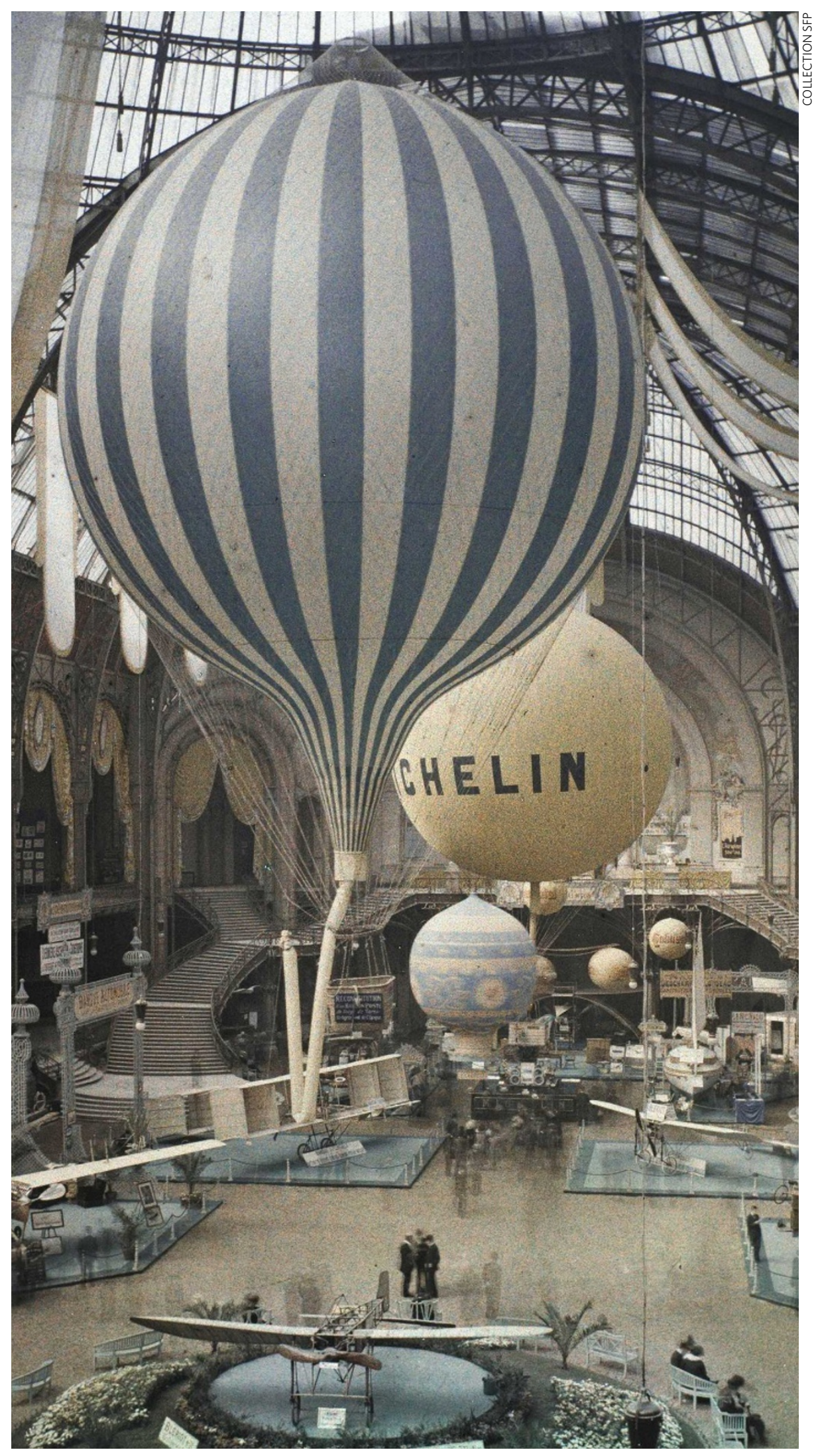

Gimpel's autochrome of the first 'Exposition Internationale de Locomotion Aérienne' in Paris, 1909. 